\title{
Design and Analysis of A Microwave Dual Band Microstrip Patch Antenna (MPA) for Wireless Communication Applications
}

\author{
${ }^{1}$ Abdurrahim ERAT \\ ${ }^{1}$ Faculty of Engineering, Department of Electrical and Electronics Engineering (PHD Student) Gaziantep University, Turkey \\ ${ }^{1}$ Şırnak Vocational College, Department of Electrical and Energy, Şırnak University, Turkey
}

\begin{abstract}
This paper presents the design and simulation of a microstrip patch antenna (MPA) which is modeled by placing several rectangular copper layer with conductive characteristics on a substrate material with dielectric constant 3.0 and $22 \times 18 \times 1 \mathrm{~mm}^{3}$ geometry. This microstrip path was designed with copper material which had a very thin thickness for patch and ground. In this study, a change in resonance frequency and return loss characteristics were observed for several substrate thickness values. The radiation characteristics of the single and dual band microstrip patch antennas (MPAs) are analysed in the frequency range of $5-25 \mathrm{GHz}$. The microstrip patch antenna (MPA) radiate at a frequency of 15.32 $\mathrm{GHz}$ with $-45 \mathrm{~dB}$ return loss. For the designed single and dual band MPA design, some electromagnetic properties such as return loss, surface current and radiation patterns were simulated. The characteristic of goods and chattels of the proposed antenna are analyzed by using the software CST Microwave Studio.
\end{abstract}

Key words: Microwave, Wideband, Dual Band, Return Loss, Wireless, Communication.

\section{Introduction}

Nowadays, the wireless data exchange has increased considerably due to the different methods for the occurrence and use of the data very high demands for high speed wireless communication have increased [1][9]. A MPA has been broadly put in an application for contemporary wireless communication systems on account of its worthiness of nominal fabrication expenditure, nominal silhouette, and unchallenging assembling with circuits [3][8]. For wireless communication, there is a need for efficient antenna transmitting and receiving data at the highest data transfer rates and lower transmission power [1]. Data transmission designs operating at Gigahertz operating frequencies $(\mathrm{GHz})$ provide wide bandwidth, high data rate and secure data transmission. MPA designs with small dimensions are ideal systems for this situation [4]. MPAs are far-reaching used in a great deal wireless designs due to their simple design, low cost production, light weight and integration with other circuits and components [1][6][9].

Dual-band and multi-band MPAs are significant momentousness to present-day wireless communication systems that set to work in more than one frequency band, since they can save the magnitude engaged by the antennas, thereby they bring down the dimensions of the undivided systems [2][7]. 
In this article, a MPA design with dual band characteristic is realized. This microstrip antenna design consists of three layers. The first patch layer consists of several conductive copper rectangular blocks and f-shaped piece. The second layer is a F4B substrate material with a dielectric constant of 3.0 and a dimension of $22 \times 18 \times 1 \mathrm{~mm}^{3}$. The last layer part which is the ground layer is the same as the patch layer. The part that is different in this layer is the lowest part of the ground layer. This part is formed by overlapping two spheres with an y-radius of $2 \mathrm{~mm}$ and an $\mathrm{x}$-radius of $8.7 \mathrm{~mm}$.

\section{The Proposed Design Of Patch Antenna}

The MP of the produced antenna is printed on one side of an F4B substrate. The substrate material has a close-packed size of $18 \times 22 \times 1 \mathrm{~mm}^{3}$ with a relative permittivity of 3.0. The MPA basically consists of several rectangular sheets and an F-shape. There are three rectangular blocks which have size $0.6 \times 5.6 \mathrm{~mm}^{2}$ and different two rectangular shape which have size respectively $0.6 \times 4.2$ $\mathrm{mm}^{2}$ and $0.6 \times 2.8 \mathrm{~mm}^{2}$ located to the top of the f-sahape. And two rectangular block which have size $1 \times 7.6 \mathrm{~mm}^{2}$ located right and left sides of the F-shapped MPA. And also there are five circles with a radius of $0.8 \mathrm{~mm}$ on the rectangular block at the top and on the right and left of the f-shape. The ground part of the MPA has almost the same configuration of patch part of the antenna. The only difference between the patch and the ground is the part at the bottom of the shape of $\mathrm{F}$ in the ground. This part is formed by overlapping two spheres with an y-radius of $4 \mathrm{~mm}$ and an $\mathrm{x}$-radius of $8.7 \mathrm{~mm}$. All widths of the F-shaped patch are equal to $h$. The structure of F-shaped MPA is shown in Fig. 1 and the dimensions of the antenna are given in the Table 1 [1].

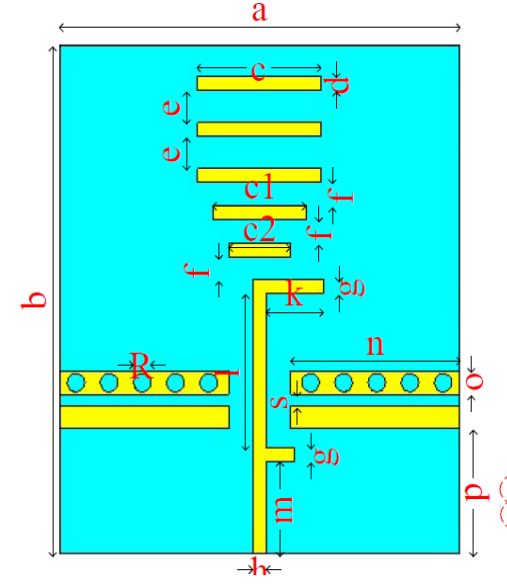

(a)

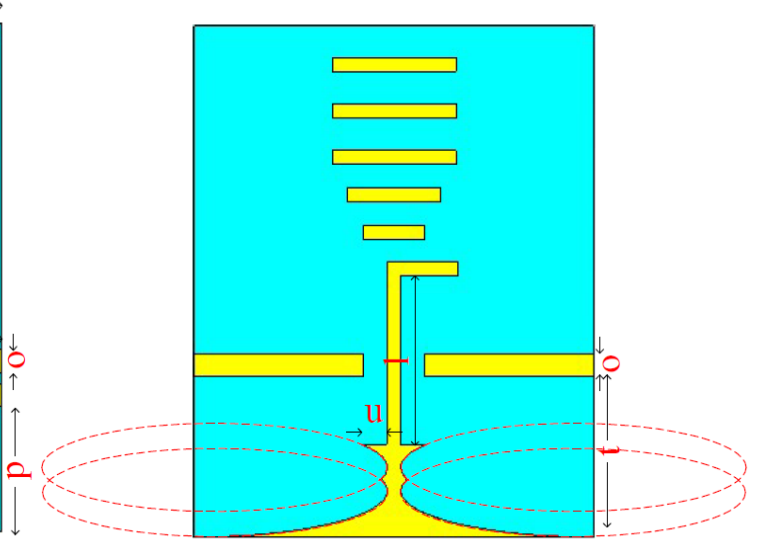

(b)

Figure. 1. Referance proposed design MPA (a) Top view and (b) bottom view.

Table 1. Dimensions of Parameter For Proposed Patch Antenna

\begin{tabular}{ccc}
\hline Project & Parameters & Size (mm) \\
\hline Rectangular blocs & {$[\mathrm{c}, \mathrm{c} 1, \mathrm{c} 2, \mathrm{~d}, \mathrm{e}, \mathrm{f}]$} & {$[5.6,4.2,2.8,0.6,1.4,1.4]$} \\
Strip patch & {$[\mathrm{p}, \mathrm{o}, \mathrm{n}, \mathrm{s}, \mathrm{R}]$} & {$[5.5,1,7.6,0.5,0.8]$} \\
F-Shape (top) & {$[\mathrm{h}, \mathrm{k}, \mathrm{g}, 1, \mathrm{~m}, \mathrm{u}]$} & {$[0.6,2.6,0.6,6.65,4,1.3]$} \\
F-Shape (bottom) & {$[\mathrm{t}, \mathrm{o}, \mathrm{u}]$} & {$[6.9,1,1.3]$} \\
\hline
\end{tabular}


Figure 2 shows the return loss graph of the dual band characteristic microstrip antenna. As can be seen from the return loss graph, the resonance frequency value is $15.32 \mathrm{GHz}$ and the value of the $\mathrm{S}$-parameter corresponding to this frequency value is $-42.78 \mathrm{~dB}$. This return loss value (the value of parameter S11) indicates that the electromagnetic wave transmission sent to the microstrip antenna by the port is performed at a perfect rate. The transmitted electromagnetic signals are perfectly transmitted by the microstrip antenna inasmuch as a very small proportion of the electromagnetic signals transmitted by the port are reflected back. On the other hand, as shown in Figure 2, two resonance frequencies are shown, the first being $15.32 \mathrm{GHz}$ and the second being $20.1 \mathrm{GHz}$. The first one is the dominant resonance frequency value of $15.32 \mathrm{GHz}$ and the second one is the resonance frequency value which is recessive with respect to the first resonance frequency value. The designed MPA achieves a characteristic transmission at the first resonance frequency $(15.32 \mathrm{GHz})$, mostly. In this way, microstrip antenna designs with two resonance frequency values represent microstrip antenna designs that demonstrate dual band characteristics.

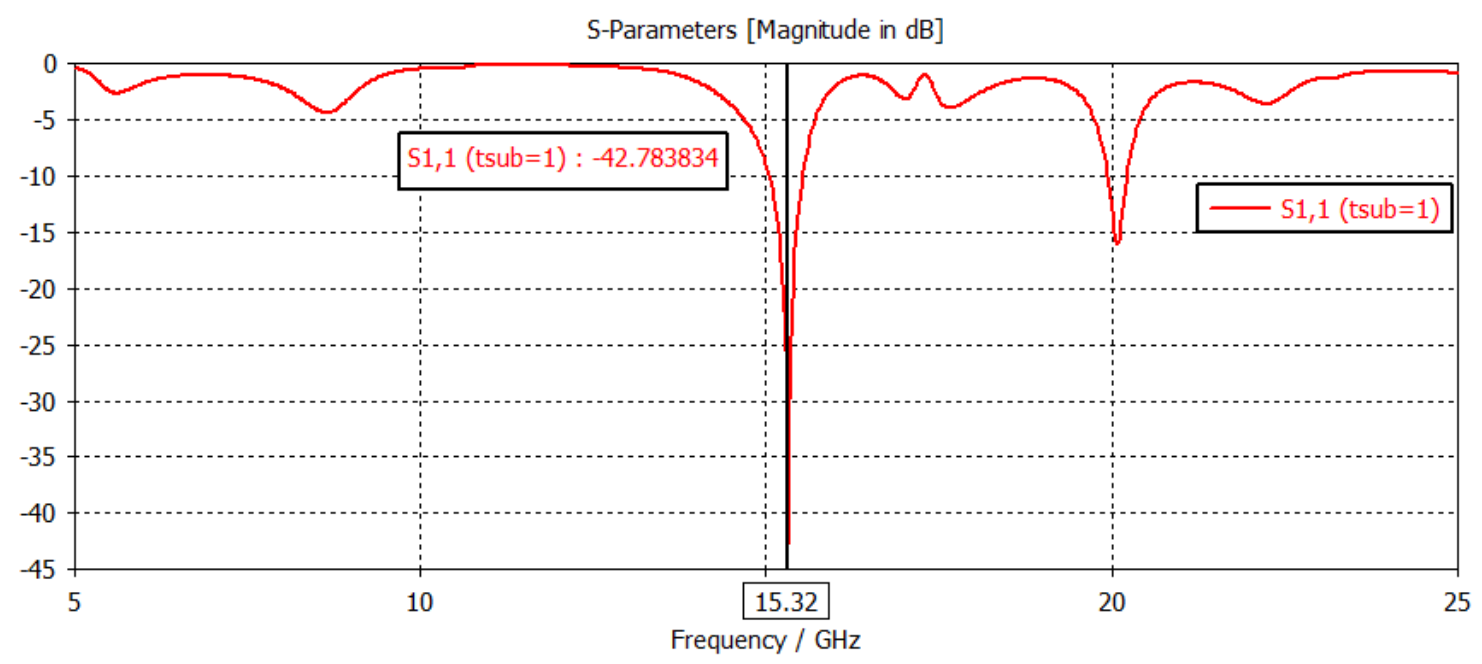

Figure. 2. Resonance frequency and return loss value for MPA design

\section{Simulated Results For Dual Band MPA}

\subsection{Substrate Thickness Variation}

The effect of the thickness of F4B substrate material on the variables such as return loss and resonance frequency of the microstrip antenna was investigated for the dual band characteristic microstrip antenna. Thickness values of $0.6 \mathrm{~mm}, 0.8 \mathrm{~mm}, 1 \mathrm{~mm}, 1.2 \mathrm{~mm}$ and $1.4 \mathrm{~mm}$ were selected for the thickness of the substrate, and return loss and resonance frequency values corresponding to these substrate thickness values were observed. The selected substrate thicknesses and the corresponding parameter values of the microstrip antenna corresponding to these values are given in Table 2. On the other hand, the selected substrate thickness values and the return loss and resonance frequency values corresponding to these thickness values are given in Figure 3 . The graph shows the color curves for each thickness value. 
Table 2. Dimensions of Substarte Thickness for Proposed Patch Antenna

\begin{tabular}{ccc}
\hline Substrate Thickness $(\mathbf{m m})$ & Resonance Frequency(GHz) & Return Loss (S1.1) (dB) \\
\hline 0.6 & 20.66 & -18.37 \\
0.8 & 20.32 & -28.63 \\
1 & 15.32 & -42.78 \\
1.2 & 15.26 & -31.74 \\
1.4 & 15.14 & -19.20 \\
\hline
\end{tabular}

As can be seen from the graph in Figure 3, the substrate thickness value is $1 \mathrm{~mm}$ for optimal data transmission. The best data transmission occurs at this substrate thickness. Resonance frequency decreases with substrate thickness values over $1 \mathrm{~mm}$. The values of the transmission losses corresponding to these shrinking resonance frequency values also increase. That is, while the transmitted data decreases, the values of the reflected data increase. In addition, resonance frequency values increase at values below $1 \mathrm{~mm}$ substrate thickness, while data transmission losses corresponding to these resonance frequency values increase. As a result, in order to obtain the best data transmission, the substrate thickness should be $1 \mathrm{~mm}$.

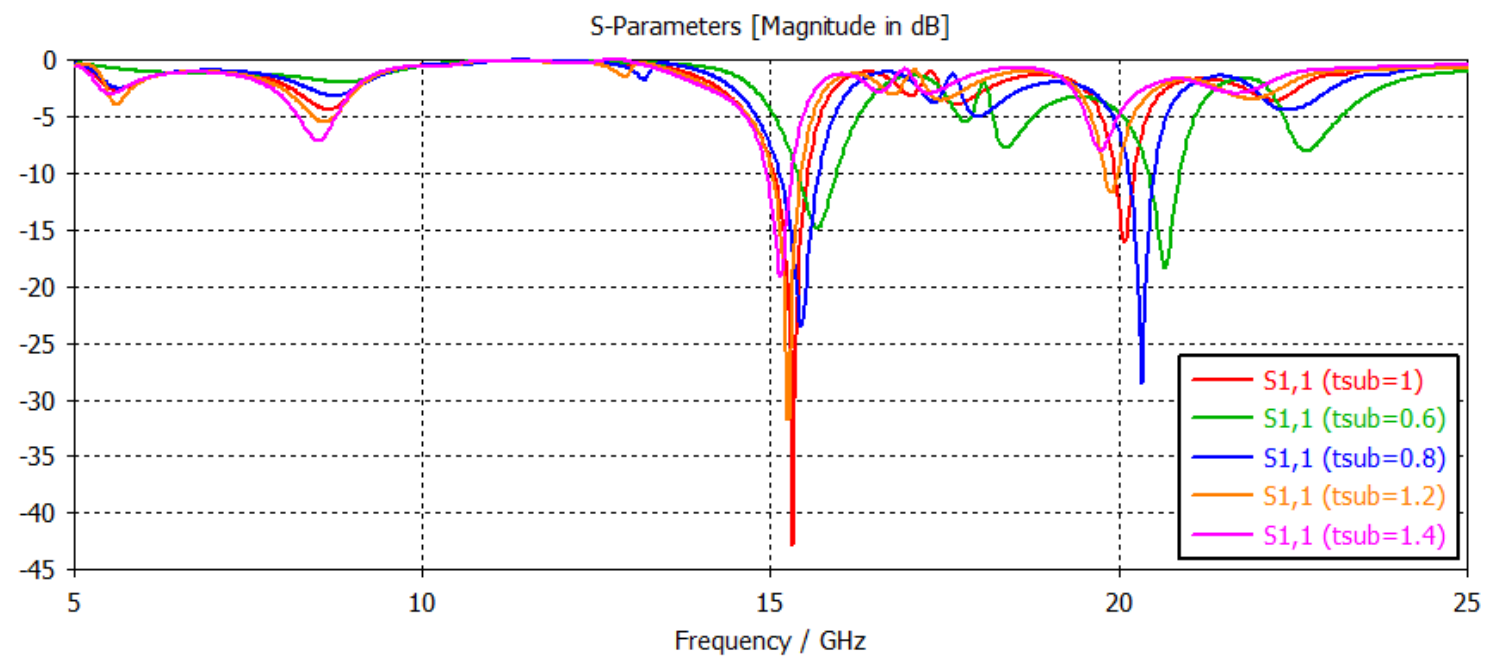

Figure. 3. Resonance frequency and return loss values for different substrate thickness values

\subsection{F-Shape Patch Width Variation}

We further investigate the effect of the width of the F-sahapped patch antenna in the return loss characteristic and resonance frequency. It is observed that the change of S-parameters characteristics by changing the width of the patch antenna. When the patch width is increased, it is seen that the resonance frequency shifts from $15.32 \mathrm{GHz}$ to $14.84 \mathrm{GHz}$. Despite the fact that the resonance frequency shifts from $15 \mathrm{GHz}$ to $14 \mathrm{GHz}$, return loss values shift from $-42.78 \mathrm{~dB}$ to -15 $\mathrm{dB}$. Resonance frequency values and Return Loss $(\mathrm{dB})$ values for different patch widths are given in Table 3. 
Table 3. Dimensions of F-Shape Patch Width for Proposed Patch Antenna

\begin{tabular}{ccc}
\hline F-Shape Patch Width $(\mathbf{m m})$ & Resonance Frequency $(\mathbf{G H z})$ & Return Loss $(\mathbf{S 1 . 1})(\mathbf{d B})$ \\
\hline 0.6 & 15.32 & -42.78 \\
0.7 & 15.22 & -35.84 \\
0.8 & 15.04 & -21.50 \\
0.9 & 14.84 & -15.96 \\
\hline
\end{tabular}

Figure 4 shows the resonance frequency and return loss behavior of the designed antenna due to changing the width of the F-shaped patch part of the antenna. When the patch width is selected as $0.6 \mathrm{~mm}$, the designed antenna achieves maximum data transmission. The data loss for this patch width value is $-42.78 \mathrm{~dB}$. When the width of the F-shaped patch is increased for the proposed antenna design, the resonance frequency behaves in the direction of decrease. Due to this behavior, there is a decrease in data transmission. In other words, there is an increase in the return loss value. The characteristic response of the designed antenna due to the variation of the width of the Fshaped patch is given in Figure 4.

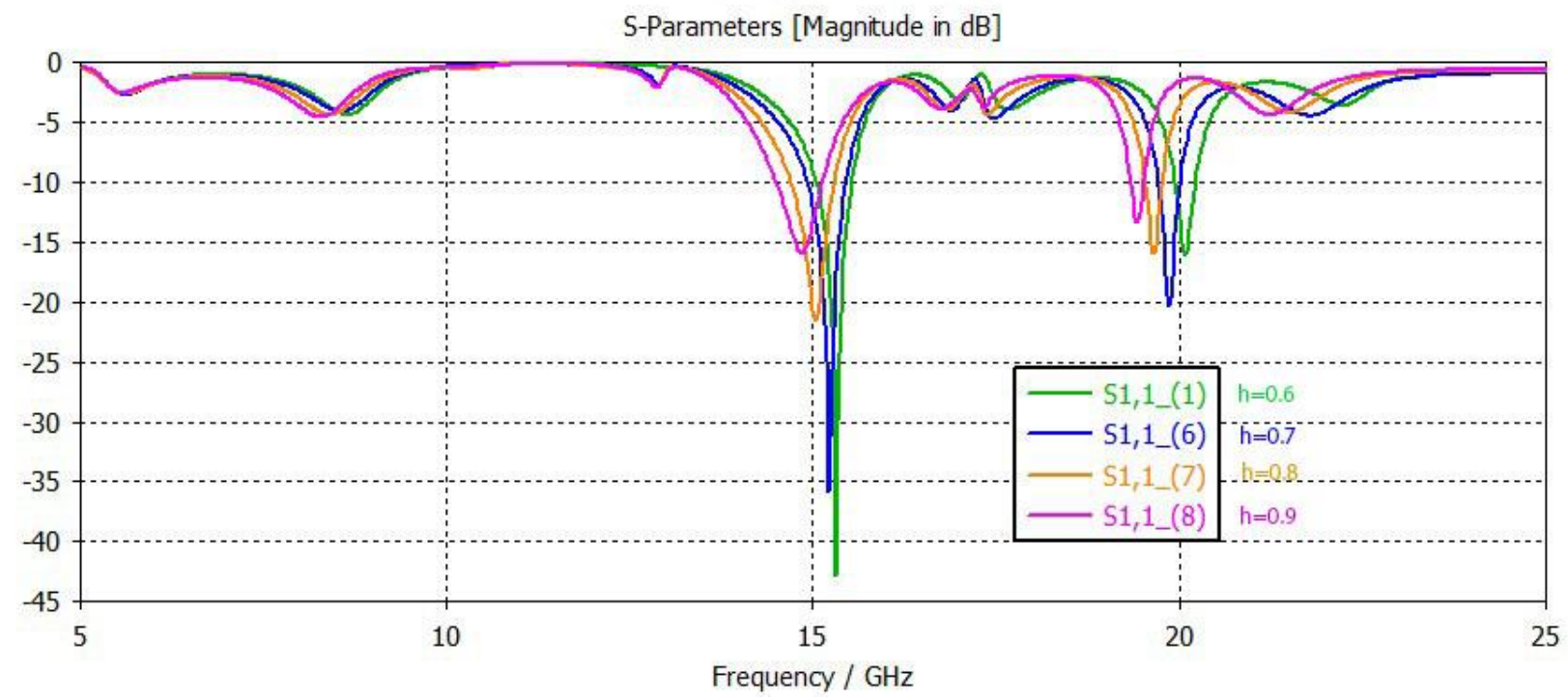

Figure 4. Resonance frequency and return loss values for different f-shape width values

\subsection{Measured normalized radiation patterns and surface current of the proposed antenna}

Figure 4 shows the simulations of the electric field and magnetic field behavior for the resonant frequency of $15.2 \mathrm{GHz}$ of the microstrip antenna with dual and broadband characteristics. Figure 4 shows the simulations of the electric field and magnetic field behavior for the resonant frequency of $15.2 \mathrm{GHz}$ of the microstrip antenna with dual and broadband characteristics. Similarly, the surface current value is given for the resonance frequency of $15.2 \mathrm{GHz}$ of the microstrip antenna with dual band characteristic designed in Figure 5. 


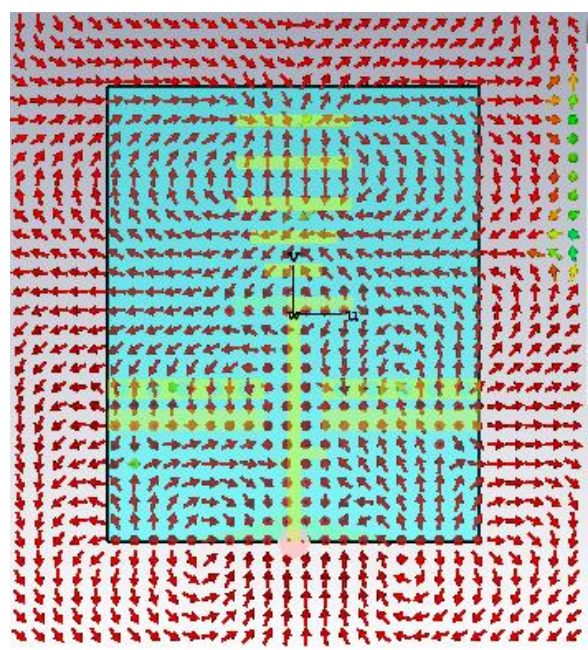

(a)

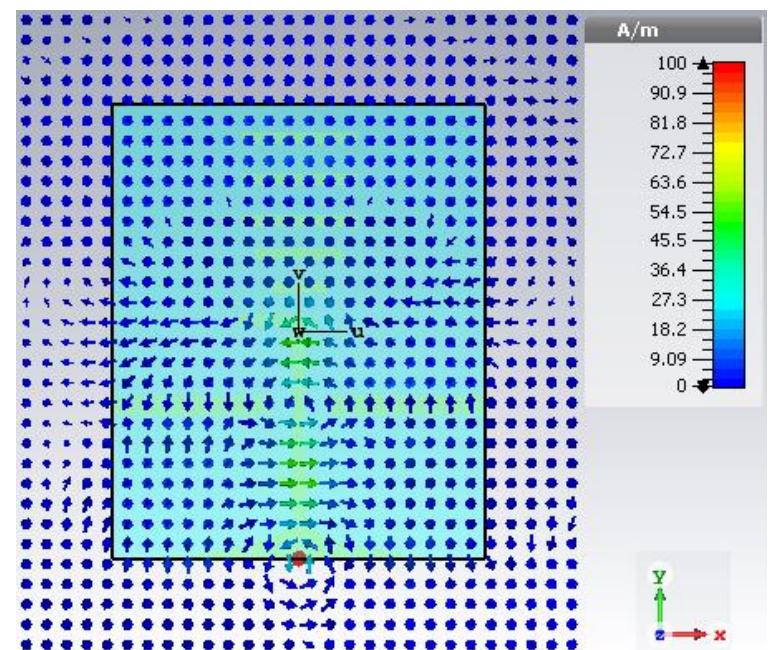

(b)

Figure 5. Simulated E-field and $\mathrm{H}$-field at $15.2 \mathrm{GHz}$ (a) E-field (b) H-field

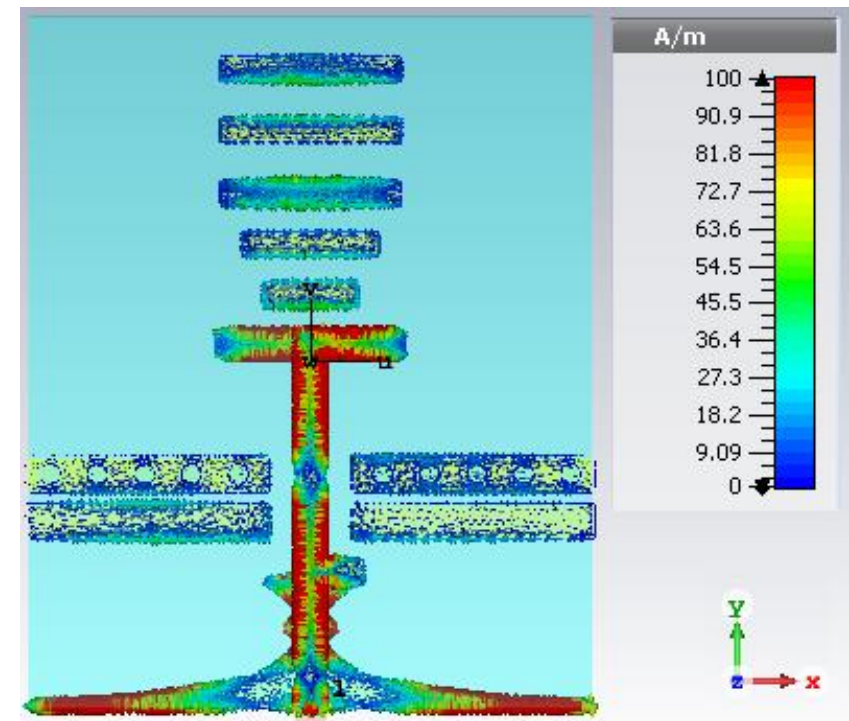

Figure 6. Simulated surface current distribution at the resonant frequency of $15.2 \mathrm{GHz}$.

\subsection{Radiation Patterns Simulations}

In Figure 6, the radiation pattern characteristics of electric field, magnetic field, gain and directivity behaviors are given for MPA with dual and broad band characteristics. 


\section{N. CAGLAR et al.//ISITES2019 SanliUrfa - Turkey}

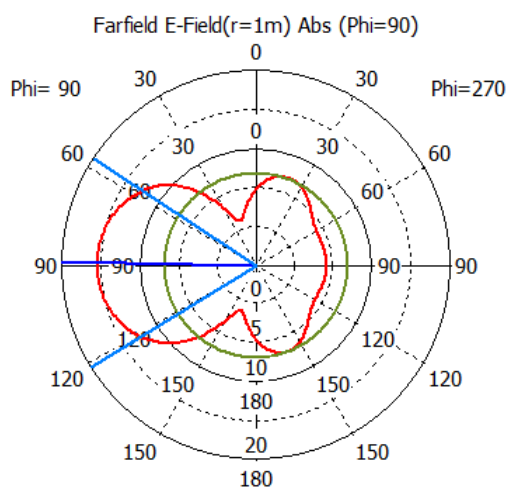

Theta / Degree vs. dBV/m

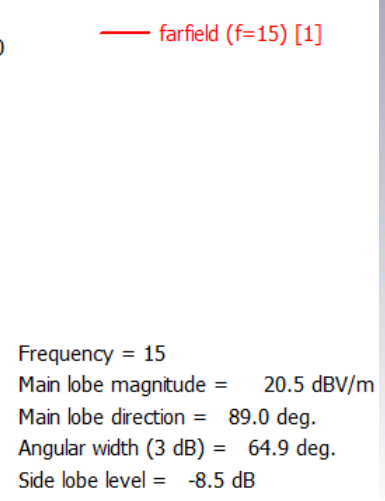

(a)

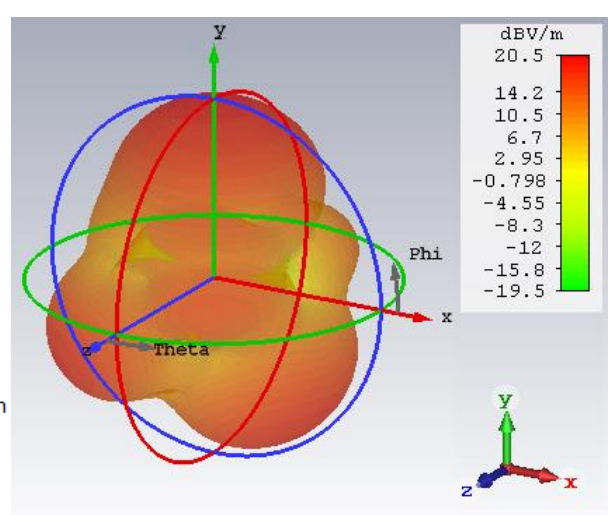

Farfield $\mathrm{H}$-Field $(\mathrm{r}=1 \mathrm{~m})$ Abs $($ Phi $=90)$

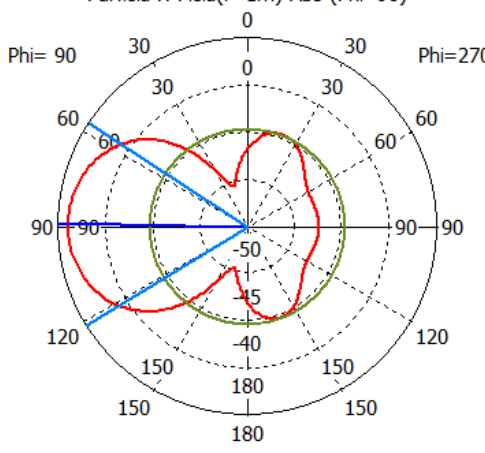

Theta / Degree vs. dBA/m

Frequency $=15$

Main lobe magnitude $=-31.1 \mathrm{dBA} / \mathrm{m}$

Main lobe direction $=89.0 \mathrm{deg}$.

Angular width $(3 \mathrm{~dB})=64.9 \mathrm{deg}$.

Side lobe level $=-8.5 \mathrm{~dB}$
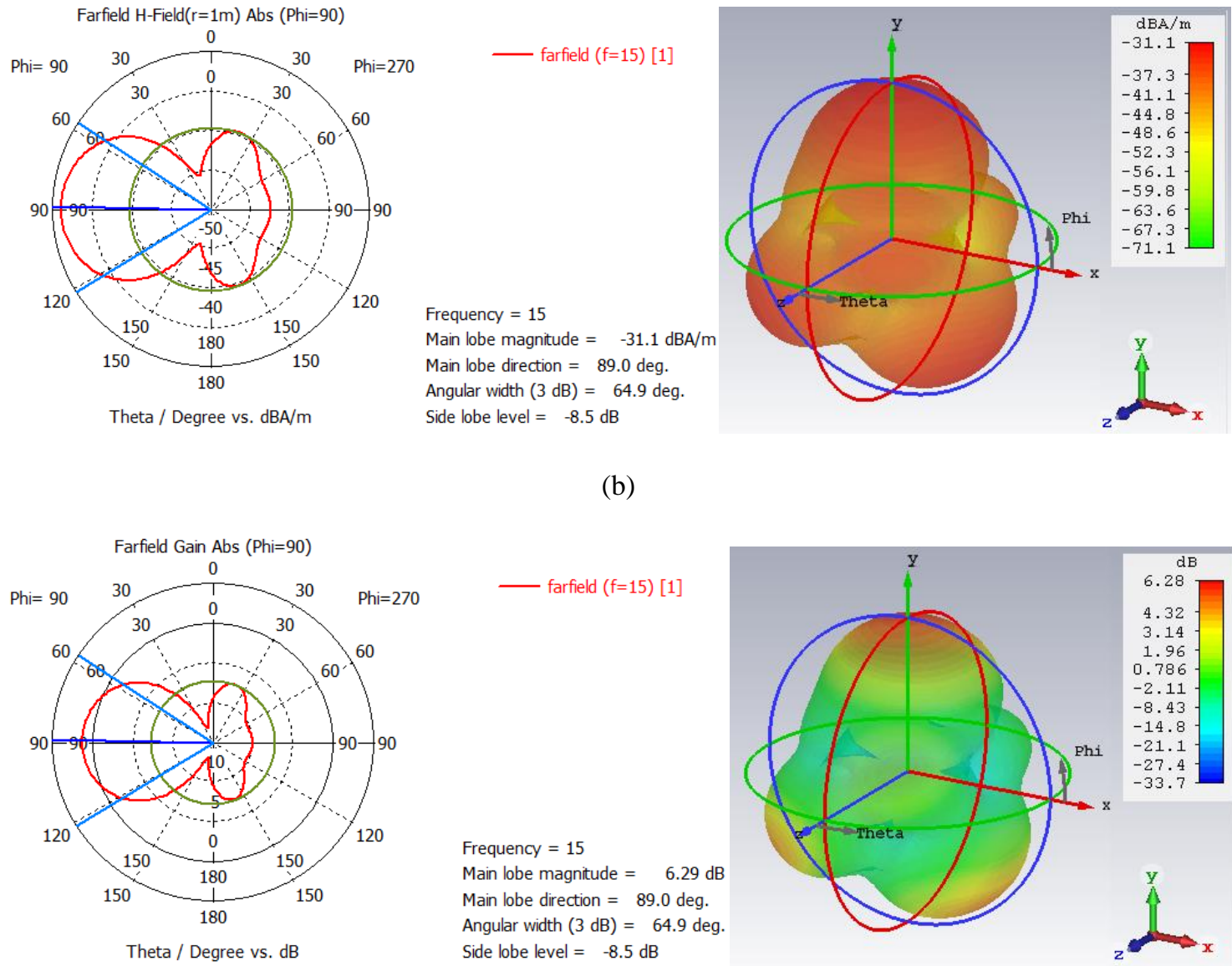

(b)

\section{)}
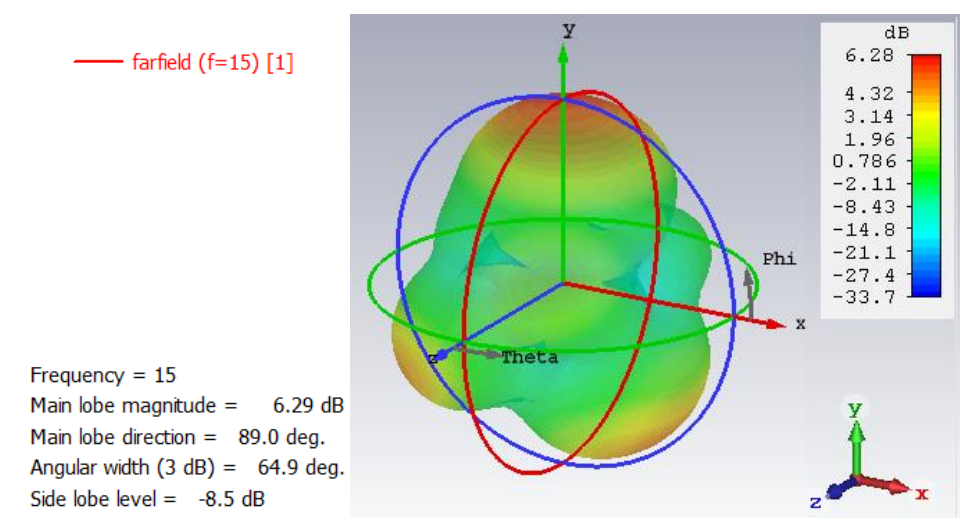

(c) 


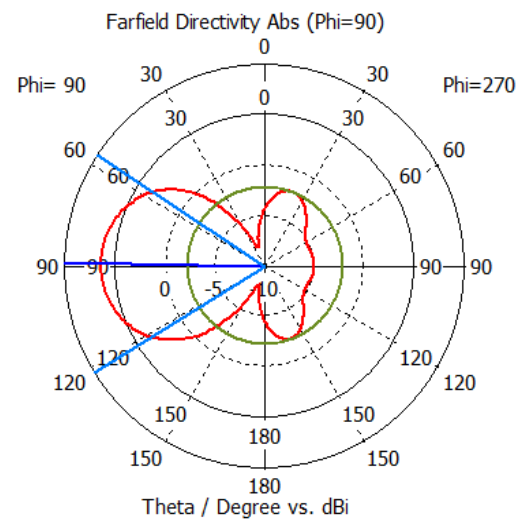

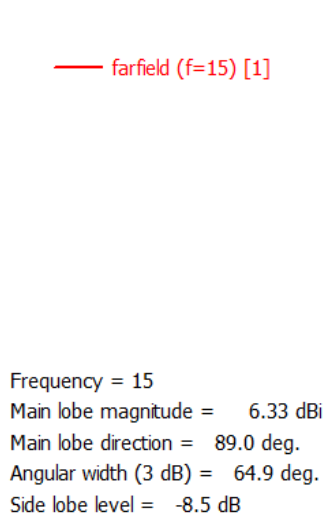

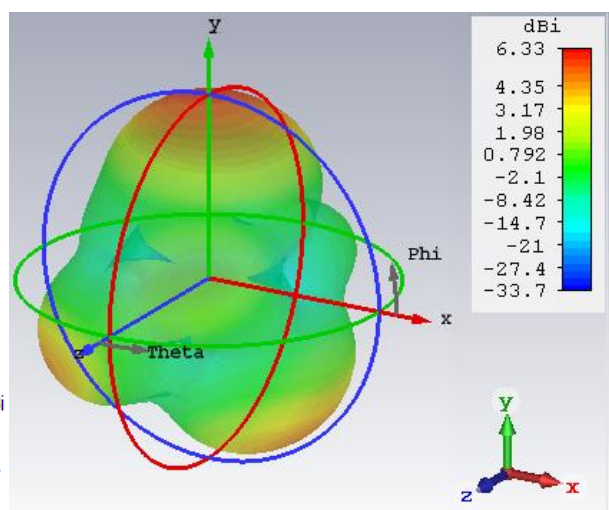

(d)

Figure 7. Simulated band radiation patterns at $15.2 \mathrm{GHz}$ (a) E-field (b) H-field (c) Gain (d) Directivity.

\section{Conclusion}

The proposed MPA is designed using the CST Studio Suite program. All the simulations were performed by using this software (CST Studio Suite). The designed antenna showed two band characteristics, one dominant and the other recessive. When the thickness of the substrate material for the designed microstrip path antenna is selected as values less than $1 \mathrm{~mm}(0.8 \mathrm{~mm}$ and $0.6 \mathrm{~mm})$, there is a tendency towards an increase in the resonance frequency. However, in response to this increasing resonance frequency, the amount of data transmitted by the designed antenna is reduced. In addition, when the thickness of the substrate material is increased $(1.2 \mathrm{~mm}$ and $1.4 \mathrm{~mm}$ substrate thicknesses are selected), both the resonance frequency and the data transmission of the MPA show a characteristic behavior in the direction of reduction. In the light of these datas, it is possible to say that $1 \mathrm{~mm}$ substrate thickness is the best thickness for data transmission of the designed patch antenna.

The effect of the width of the F-shaped patch on the resonance frequency and return loss values of the microstrip antenna was investigated. For this purpose, several simulation analyzes were performed for several patch width values $(0.6 \mathrm{~mm}, 0.7 \mathrm{~mm}, 0.8 \mathrm{~mm}$, and $0.9 \mathrm{~mm})$. When these analyzes were performed, the resonance frequency decreased due to the increase of the width of the patch. In response to these decreasing resonance frequency values, the return loss values of the antenna decreased. In other words, when the patch thickness is increased, the resonance frequency and the data transmission of the antenna decrease. Based on this data, we can say that the best patch thickness of the patch antenna is $0.6 \mathrm{~mm}$ for the best data transmission. All these analyzes show that the designed microstrip antenna is an excellent design for wireless data transmission. 


\section{References}

[1] J. Xu, M. Zhao, R. Zhang, M. Lei, X. Gao, S. Huang, and K. Bi. "A Wideband F-Shaped Microstrip Antenna”. Ieee Antennas And Wireless Propagatıon Letters. 2017. Vol. 16.

[2] T.Bhattacharjee, H. Jiangand N. Behdad." A Fluidically Tunable, Dual-Band Patch Antenna With Closely Spaced Bands of Operation". Ieee Antennas And Wireless Propagation Letters. 2016. Vol. 15.

[3] H. Kim, H. Wi, S. Wang, and J. Kim. "Broadband 3 dB microstip hybrid coupler with low dielectric substrate for X-band applications," in Proc. IEEE Wireless Microw. Technol. Conf. 2016. pp. 1-3.

[4] R. Saha, S. Maity, and N. Trigunayat. "Enhancement of gain, bandwidth and directivity of a patch antenna by increasing dielectric layers of the substrate through micromachining technique for RFID application", in Proc. Int. Conf. Adv. Comput. Eng. Appl. 2015. pp. 321-324.

[5] L. Xing, Y. Huang, Q. Xu, and S. Alja'Afreh. "A wideband hybrid water antenna with an Fshaped monopole," IEEE Access. 2015. vol. 3, pp. 1179-1187.

[6] N. M. Awad and M. K. Abdelazeez. "Multislot microstrip antenna for ultra-wide band applications," J. King Saud Univ.—Eng. Sci., doi: 10.1016/j.jksues.2015.12.003

[7] Y. Li and J. Wang. "Dual-Band Leaky-Wave Antenna Based on Dual- Mode Composite Microstrip Line for Microwave and Millimeter-Wave Applications". Ieee Transactions On Antennas And Propagatıon. , 2018. Vol. 66, No. 4

[8] C. Deng, X. Lv, and Z. Feng. "Wideband Dual-Mode Patch Antenna With Compact CPW Feeding Network for Pattern Diversity Application". Ieee Transactions On Antennas And Propagatıon. 2018. Vol. 66, No. 5.

[9] J. Chen, K. Tong, A. Armaghany, and J. Wang. "A Dual-Band Dual-Polarization Slot Patch Antenna for GPS and Wi-Fi Applications". Ieee Antennas And Wireless Propagation Letters. 2016. Vol. 15. 